\title{
Metodologias ativas na formação do professor de Educação Física
}

\section{Active methodologies in training of Physical Education teacher}

\author{
${ }^{1}$ Luciana Santos Collier lucianacollier@gmail.com \\ ${ }^{2}$ Claudia Teresa Vieira de Souza
}

\section{RESUMO}

O presente artigo discute o desenvolvimento e os desdobramentos da disciplina 'Atividade Física e Promoção da Saúde’, no curso de Licenciatura em Educação Física, de uma Instituição de Ensino Superior (IES) e suas aproximações com as Metodologias Ativas de ensino. A disciplina foi idealizada baseando-se na Aprendizagem Baseada em Problemas (ABP) e na metodologia da problematização. As atividades de pesquisa teórica e de campo realizadas durante o desenvolvimento da disciplina provocaram discussões de fundamental importância para a compreensão dos limites e possibilidades da atuação do professor de Educação Física na promoção da saúde, em seus diferentes contextos de ação. A disciplina foi desenvolvida durante dois semestres consecutivos, gerando desdobramentos importantes para a formação de todos os sujeitos envolvidos. Somente "mergulhando” no campo, através de pesquisas, entrevistas e observações, foi possível fazer as reflexões necessárias à construção de uma análise crítica da referida atuação.

Palavras-chave: Educação física. Metodologias ativas. Aprendizagem baseada em problemas. Problematização.

\begin{abstract}
This article discusses the development and the unfolding of the discipline 'Physical Activity and Health Promotion', in the Physical Education Degree, at a higher education institution and its relationship to active teaching methodologies. The course was designed based on the Problem Based Learning (PBL) and the problematization methodology. The theoretical research and the field activities during the development of the discipline brought about fundamental importance of discussions to understand the limits and possibilities of the physical education teacher action in health promotion, at their different contexts of action. The discipline was developed over two consecutive semesters, generating important consequences for the training of all actors involved. Only "dipping" in the field, through surveys, interviews and observations, it was possible to make the reflections needed to build a critical analysis of that performance.
\end{abstract}

Keywords: Physical education. Active methodologies. Problem based learning, Problematization.

1 Colégio Universitário Geraldo Reis (COLUNi/UFF), Doutora em Ensino em Biociências e Saúde pelo Instituto Osvaldo Cruz/Fiocruz.

2 Pesquisadora Titular em Saúde Pública da Fundação Oswaldo Cruz (Fiocruz), Chefe do Laboratório de Pesquisa em Epidemiologia e Determinação Social da Saúde do Instituto Nacional de Infectologia Evandro Chagas/Fiocruz, Docente do Programa de Pós-Graduação em Ensino em Biociências e Saúde do Instituto Oswaldo Cruz/Fiocruz 


\section{INTRODUÇÃO}

Nas últimas décadas, a educação de profissionais da saúde tem sido motivo de grande preocupação, devido à dificuldade da formação em corresponder às demandas sociais. Por este motivo as políticas públicas têm ressaltado a necessidade de mudança na formação dos profissionais de saúde, apontando para a implementação de currículos integrados e voltados às necessidades da população (DELLA BARBA et al., 2012).

Conterno e Lopes (2013) recordam que, em meados dos anos 1990, as instituições de ensino superior (IES) e demais instituições formadoras de nível técnico, começaram a ser convocadas a mudar suas práticas pedagógicas, numa tentativa de se aproximarem da realidade social e de motivarem professores e alunos a tecerem novas redes de conhecimentos. No contexto do ensino superior, a Lei de Diretrizes e Bases da Educação Nacional (LDB) junto com as Diretrizes Curriculares Nacionais (DCN) passaram a pautar as modificações necessárias nos cursos de graduação, de uma forma geral. Voltadas especificamente para a área da saúde, a Política Nacional de Educação Permanente em Saúde e o Programa Nacional de Reorientação da Formação Profissional em Saúde (Pró-Saúde) direcionaram-se para a promoção de mudanças na formação dos profissionais de saúde no Brasil, tendo como parâmetro, o Sistema Único de Saúde (SUS).

Neste cenário, ficou indicada a necessidade de estimular no profissional da saúde a conhecer os problemas do mundo atual (nacional e regional) e a prestação de serviço à população, estabelecendo com ela uma relação de reciprocidade (CONTERNO; LOPES, 2013). Neste sentido, as abordagens pedagógicas progressivas foram sendo construídas com o objetivo de formar profissionais que fossem sujeitos sociais dotados não somente de competências éticas, políticas e técnicas, mas também de conhecimento, raciocínio, crítica, responsabilidade e sensibilidade para as questões da vida e da sociedade, com capacidade de intervir em contextos de incertezas e complexidades (MITRE et al., 2008).

A partir desta contextualização o presente artigo discute o desenvolvimento e os desdobramentos da disciplina Atividade Física e Promoção da Saúde, no curso de Licenciatura em Educação Física da Universidade Federal Fluminense (UFF), no município de Niterói, Rio de Janeiro no ano de 2012 e suas aproximações com as Metodologias Ativas de ensino.

\section{METODOLOGIAS ATIVAS NO ENSINO SUPERIOR}

Borges e Alencar (2014) endossam a ideia de pensar novas propostas para o ensino superior que tenham como objetivo "educar para a autonomia, através de metodologias inovadoras, para a descoberta, utilizando-se da pesquisa, participação dos alunos, trabalhos em grupo, como um meio de aprofundar e resinificar os conhecimentos” (p.120).

Mitre et al. (2008) defendem que o estudante deve ser orientado a se livrar da atitude de mero receptor de conteúdos, buscando assumir um papel mais ativo na construção de conhecimentos, que sejam relevantes e ao mesmo tempo contemplem os objetivos da aprendizagem. Iniciativa criadora, curiosidade científica, espírito crítico-reflexivo, capacidade para autoavaliação, cooperação para o trabalho em equipe, senso de responsabilidade, ética e sensibilidade na assistência são características fundamentais a serem desenvolvidas em seu perfil (KOMATZU, ZANOLLI e LIMA, 1998).

Ribeiro e Júnior (2016) acrescentam que o contato de graduandos com ambientes extrauniversitários deve ocorrer, não apenas em momentos pontuais, mas ao longo de toda formação, a fim de que o processo de formação possibilite a potencialização do conhecimento teórico a partir da vivência prática. Pensando na formação dos profissionais de saúde, a ideia é que o processo de ensino esteja vinculado aos cenários da prática e presente ao longo de toda a carreira. Assumir esse novo modelo implica o enfrentamento de novos desafios, como a constru- 
ção de um currículo integrado, em que o eixo da formação articule a tríade prática-trabalho-cuidado, direcionando-se para uma consideração de interpenetração e transversalidade (MITRE et al., 2008; VIEIRA et al, 2016).

Tais reflexões sugerem a adoção de Metodologias Ativas nas disciplinas ministradas no ensino superior. Berbel (2011) acrescenta que "as metodologias ativas têm o potencial de despertar a curiosidade, à medida que os alunos se inserem na teorização e trazem elementos novos, ainda não considerados nas aulas ou na própria perspectiva do professor” (p.28).

Conterno e Lopes (2013) acrescentam que "no campo da saúde, está se forjando um consenso de que as autodenominadas metodologias inovadoras, respaldadas pelo não diretivismo pedagógico, poderão responder, de forma progressista, aos problemas da formação superior dos profissionais da área (p.518)”. Para estes autores a incorporação ou a adesão acrítica das 'metodologias ativas' sem uma avaliação mais criteriosa e contextualizada dos desdobramentos políticos e pedagógicos para a formação de futuros profissionais da saúde, pode trazer consequências desastrosas. A incorporação de pressupostos pedagógicos sem a devida reflexão sobre aspectos teóricos que os embasam pode produzir efeitos danosos a qualquer processo de formação, seja ele formal ou informal, na saúde ou em outra área, uma vez que o 'ecletismo pedagógico’, pode produzir confusões e contradições (CONTERNO; LOPES, 2013).

Em nosso entendimento, as metodologias ativas, não podem ser usadas de forma acrítica e em qualquer contexto ou situação de ensino indiscriminadamente. Há que se ter objetivos claros, habilidades e competências bem definidas e situações específicas para optar pelas metodologias ativas. Além disso, de forma alguma, o fato do aluno ou grupo de alunos assumir o protagonismo do processo de ensino, significa que o professor estará ausente do mesmo. O não diretivismo não pode, neste caso, significar ausência de intencionalidade pedagógica do professor, mas sim a liberdade de escolha do aluno na descoberta do melhor percurso para atingir o objetivo. O professor orientador deve ser parceiro na descoberta e componente indispensável do grupo na construção coletiva do conhecimento, tendo inclusive a importante função de correção do rumo, quando o percurso utilizado na busca do conhecimento se afasta muito do objetivo a ser alcançado.

\section{APRENDIZAGEM BASEADA EM PROBLEMAS E PROBLEMATIZAÇÃO}

De acordo com Cyrino e Toralles-Pereira (2004) a problematização e a ABP são duas propostas distintas, dentro das Metodologias Ativas, que "trabalham intencionalmente com problemas para o desenvolvimento dos processos de ensinar e aprender” (BERBEL, 1998, p. 141) e estão apoiadas na aprendizagem por descoberta e significativa, valorizando o 'aprender a aprender'.

A ABP se propõe a reestruturar o currículo, integrando as disciplinas a partir da prática (pesquisa/intervenção/atuação). Segundo Neto (2013) a organização curricular é feita a partir de situações-problema que o aluno precisa vivenciar para aprender alguns conteúdos (temas de estudo). As situações-problema abrangem conhecimentos de diversas áreas remetendo à organização interdisciplinar do currículo.

Os problemas funcionam simultaneamente de organizadores do currículo e de estímulo à aprendizagem.

Ao tentarem compreender o problema, os alunos são levados a tomar consciência das novas aquisições conceituais e procedimentais que têm de realizar, proporcionando, desse modo, o contexto apropriado para que a necessidade de integrar conhecimento de diversas áreas de conhecimento se faça sentir (NETO, 2013 p.28).

O professor atua como facilitador ou guia do processo de aprendizagem, ajudando os alunos a colocar questões, para melhor compreenderem a natureza do problema e conseguirem chegar a possíveis soluções. A aprendizagem é realizada em pequenos grupos, na forma de trabalho colaborativo. 
A ABP estimula o aluno ser o protagonista do próprio aprendizado a partir da busca ativa de informações, integrando o conhecimento, identificando e explorando novas áreas, desenvolvendo assim habilidades técnicas, cognitivas e atitudinais para a prática profissional e também para aprender ao longo da vida (BORGES et al, 2014).

A proposta da problematização, diferente da $\mathrm{ABP}$, se constitui numa estratégia de ensino, e não numa proposta de reorganização curricular. Segundo Berbel (1998) a problematização tem como pressuposto básico levar o sujeito a refletir sobre a situação global de uma realidade concreta, dinâmica e complexa. Na educação problematizadora busca-se interpretar a realidade, voltando-se à criação de espaços contra-hegemônicos e contestatórios que possibilitem criticar a realidade estudada.

A realidade concreta é selecionada para promover a aprendizagem e para nela intervir, em busca de soluções para seus problemas. São elaboradas criativamente hipóteses de solução, das quais serão escolhidas uma ou algumas para serem colocadas em prática na parcela da realidade da qual se extraiu o problema de estudo.

Desta forma a participação do aluno se dá no exercício do aprender fazendo, onde a relação teoria-prática é constante. Mais que isso, ocorre, nesse percurso, uma dinâmica de ação-reflexão-ação, onde a ação final (intervenção) caracteriza-se como uma ação transformadora, em algum grau. Nesse sentido, o percurso é percebido como uma forma de exercitar a práxis, entendida como uma prática consciente, refletida, informada e intencionalmente transformadora (BERBEL, 1998).

Zanotto e Rose (2003) ressaltam que para problematizar não é suficiente apenas expor a situação, mas é fundamental discutir os conflitos inerentes que sustentam o problema. A problematização busca levar o sujeito ao contato com as informações e à produção do conhecimento, principalmente, com a finalidade de solucionar os impasses e promover o seu próprio desenvolvimento. Ao perceber que a nova aprendizagem é um instrumento necessário e significativo para ampliar suas possibilidades e caminhos, poderá exercitar a liberdade e a autonomia na realização de escolhas e na tomada de decisões (MITRE et al., 2008).

A simples adoção de qualquer um desses instrumentos metodológicos, por si só não consegue interromper o ciclo da fragmentação e do reducionismo do ensino tradicional. Para que transformações mais efetivas e duradouras aconteçam o currículo deve ser construído de maneira integrada, tratando temas e conteúdos numa perspectiva interdisciplinar, facilitando a integração ensino-serviço (CECCIM E FEUERWERKER, 2004). Nessa perspectiva, empreender mudanças no processo ensino-aprendizagem e na formação profissional de saúde significa transformar a relação entre docente e discente; as diversas áreas e as disciplinas; a universidade e a comunidade. (MITRE et al., 2008)

\section{A DISCIPLINA ATIVIDADE FÍSICA E PROMOÇÃO DA SAÚDE}

Berbel (2011) nos alerta que nenhuma metodologia, por mais promissora que seja pelas suas características, é capaz de promover transformações profundas na educação ou no mundo. Também não consegue, por si só, promover a motivação autônoma dos alunos. Qualquer que seja a metodologia utilizada, para que possa causar algum efeito na direção da intencionalidade pedagógica do docente, tem a necessidade

que os participantes do processo as assimilem, no sentido de compreendê-las, acreditem em seu potencial pedagógico e incluam uma boa dose de disponibilidade intelectual e afetiva (valorização) para trabalharem conforme a proposta, já que são muitas as condições do próprio professor, dos alunos e do cotidiano escolar que podem dificultar ou mesmo impedir esse intento (BERBEL, 2011 p.37).

Segundo Ribeiro e Júnior (2016) para que tais metodologias se consolidem de fato nas IES é premente o apoio de toda comunidade acadêmica. Estudo feito pelos autores aponta que muitos educadores preferem ficar 
na sua zona de conforto e permanecer ensinando ‘intramuros universitários', em situação controlada. Para os docentes que trabalham em cursos de licenciatura, uma das preocupações centrais deve ser como ensinar os conteúdos sem, perder de vista que precisam 'ensinar a ensinar', na medida em que estão inseridos no processo de formação de futuros professores.

De acordo com as diretrizes do curso de Licenciatura em Educação Física da UFF, as disciplinas são construídas de maneira a trabalhar teoria e prática de maneira integrada, buscando não dicotomizar corpo e mente e evitando a fragmentação curricular, propiciando que o conhecimento discutido numa disciplina possa ser aproveitado para a reflexão das demais. As metodologias utilizadas buscam desenvolver a autonomia através da reflexão, discussão e análise conteúdos de forma a contribuir com a integralidade do currículo e a interdisciplinaridade da proposta. Tais considerações, apresentadas sob a forma de princípios do curso, sugerem a organização de um currículo orientado pela ABP, embora, na prática, a organização curricular não seja feita exatamente assim.

O 'Manifesto ABENEFS: Alinhando a formação inicial em Educação Física às necessidades do setor saúde’ (ABENEFS, 2016) sugere ações para os diversos segmentos envolvidos com a formação inicial em Educação Física. Das ações recomendadas aos docentes do ensino superior ressaltamos aquelas, que fortalecem as práticas descritas neste relato e corroboram as nossas conclusões acerca da utilização de metodologias ativas de ensino. São elas:

1 - Discutir as ações, programas, políticas públicas de saúde e as diferentes possibilidades de atuação do profissional de Educação Física na Saúde Coletiva, considerando as propostas do Ministério da Saúde;

2 - Estimular a participação dos estudantes em disciplinas, grupos de estudo, projetos de extensão e pesquisa de outros cursos da área da saúde;

3 - Utilizar estratégias diversificadas de ensino e metodologias ativas de aprendizagem para aproximar os estudantes de vivências teórico-práticas no ensino, pesquisa e extensão;

4 - Apresentar aos estudantes possibilidades de atuação no campo da saúde.

Acompanhando este raciocínio, a disciplina ‘Atividade Física e Promoção da Saúde’ no curso de Licenciatura em Educação Física da UFF, desenvolveu-se durante dois semestres consecutivos (2012.1 e 2012.2) utilizando Metodologias Ativas de ensino para o desenvolvimento de seu programa. A fim de organizar didaticamente a abordagem dos conteúdos, a disciplina foi dividida em três momentos e, para cada um deles elaborou-se uma atividade de culminância e avaliação, baseada na problematização. Desta forma, a disciplina, gerou desdobramentos importantes para a formação de todos os sujeitos envolvidos.

\section{1 Primeiro momento}

A preocupação inicial para o desenvolvimento da disciplina era saber o que os alunos entendiam sobre saúde e promoção da saúde, e de que maneira relacionavam a atividade física com os dois primeiros conceitos. Desta forma organizou-se na primeira aula um debate sobre as concepções de saúde e de promoção da saúde na atualidade e como o professor de educação física, através da atividade física, deveria se inserir neste contexto. Esta atividade buscou identificar o que cada um dos membros do grupo sabia sobre a temática em questão (conhecimentos prévios), portanto foram anotadas as principais ideias que foram surgindo.

No mesmo dia, a fim de conhecer o que a sociedade em geral sabe sobre o assunto, os alunos saíram por alguns minutos da sala de aula com a incumbência de entrevistar 'leigos'(foi solicitado que não entrevistassem outros alunos ou professores do curso de EF), buscando saber como eles definiam saúde e promoção da saúde, e como a atividade física se relaciona com ambas. O objetivo da atividade era conhecer o que a sociedade sabe sobre o tema, para depois comparar com as ideias expostas no debate realizado anteriormente pelos alunos. 
Neste sentido, a segunda aula da disciplina foi dedicada ao exercício de comparação entre as concepções apontadas pelos alunos com aquelas colhidas através das entrevistas. A atividade deixou claro que tanto os alunos como os 'leigos' tinham ideias muito próximas sobre o tema. Embora os alunos tivessem a capacidade de elaborar melhor suas definições, o conteúdo destas era bem semelhante daquelas colhidas nas entrevistas. A partir desta constatação foram levantadas algumas questões preliminares a fim de estimular o debate e desconstruir e problematizar as ideias que surgiram, além de motivar os alunos a desenvolver pesquisas e reflexões que pudessem levá-los a uma ampliação das concepções sobre o assunto. As questões levantadas foram:

- O que seria o "perfeito estado de bem estar físico, mental e psicológico"? (este foi o conceito mais citado para saúde);

- Qual a diferença entre promoção da saúde e prevenção de doenças? (estes termos foram utilizados insistentemente durante o debate);

- Exercício sempre é saúde? (a relação entre ambos foi a mais utilizada para justificar a atividade física voltada para a 'promoção da saúde').

Tais questionamentos tiveram a intenção de gerar "conflitos internos" e provocar a reflexão sobre alguns conceitos equivocados ou rudimentares que os próprios alunos traziam em sua estrutura cognitiva, bem como outros "eternizados" pelo senso comum. O debate seguiu sem consenso e suscitou inúmeras dúvidas que foram devidamente registradas. Faltava respaldo teórico para aprofundar o debate e ultrapassar o limite do 'achismo’ o que instigou os alunos a pesquisarem sobre o assunto.

A fim de criar um novo cenário para o debate, seguiu-se um período de aprofundamento bibliográfico, baseado nas principais dúvidas registradas. Foi feito, portanto, um resgate histórico da evolução dos conceitos de saúde e de promoção da saúde, desde o homem primitivo até as concepções contemporâneas, passando pelas definições da Organização Mundial da Saúde, Declaração de Alma-Ata, Carta de Ottawa, etc. Neste momento foram utilizadas diversas estratégias de estímulo à pesquisa. A cada artigo, documento, filme ou documentário - muitas vezes sugerido pelos próprios alunos - buscava-se encontrar respostas para os questionamentos levantados anteriormente.

Ao final deste período de aprofundamento bibliográfico (6 aulas aproximadamente), a fim de avaliar se os alunos haviam compreendido e ampliado suas concepções sobre saúde e promoção da saúde, lançou-se o seguinte desafio: separados em grupos, eles deveriam elaborar um plano de promoção da saúde para uma comunidade (fictícia), envolvendo diversos setores da sociedade (saúde, educação, segurança, saneamento/meio-ambiente, infraestrutura, etc.). O desafio, que se baseou na metodologia da problematização, era pensar como os diferentes setores podem colaborar com a saúde pública. Para Neto (2013) a situação problemática sugerida deve replicar as situações problemáticas da vida real (ou ser delas extraída), ou seja, ser apresentada de forma difusa e pouco estruturada, ainda que estimulante.

Realizou-se um seminário onde cada grupo apresentou a sua proposta e discutiu com a turma sobre como os diferentes setores da sociedade podem/devem se articular a fim de promover a saúde. Esta atividade teve a finalidade de provocar a reflexão sobre as dificuldades em se planejar políticas públicas envolvendo a participação dos diversos setores da sociedade, mas também refletir e compreender como tais políticas se desenvolvem aqui no Brasil. A forma como cada grupo elaborou a sua 'política pública de saúde' deixou transparecer novos conceitos e ideias sobre saúde e promoção da saúde, ficando elucidadas também as diferenças entre promoção e prevenção da saúde. Novas concepções foram construídas pelos alunos a partir do acúmulo feito nos debates e leituras realizados.

Embora a situação-problema inicial tenha sido proposta pela professora, os problemas por ela desencadeados, ajudaram a colocar os alunos no centro do processo educativo. Debruçados sobre o problema de uma 
comunidade fictícia e com a tarefa de formular políticas públicas de saúde que atendessem as demandas da mesma, os alunos puderam compreender melhor a amplitude do conceito de saúde e a dificuldade em trabalhar a promoção da saúde. Desta forma, observou-se o desenvolvimento da autonomia, consciência crítica e capacidade de reflexão, a partir da pesquisa e discussão que se fez necessária para chegar às hipóteses de solução.

\section{2 Segundo momento}

Para reforçar o processo de aprendizagem pensou-se, para esta etapa, numa investigação in loco sobre a prática de diferentes professores de Educação Física na perspectiva da promoção da saúde. O propósito da atividade era fazer com que os alunos conhecessem os limites e possibilidades desta atuação, para, na etapa seguinte, pensar em estratégias de ensino que relacionassem a atividade física e a promoção da saúde nos diferentes contextos educativos da área.

Ao contrário da proposta anterior, onde a professora apresentou a situação problema, aqui os alunos foram descobrir no campo quais eram os problemas relacionados à promoção da saúde na Educação Física. Garlet, Cardonetti e Oliveira (2014) defendem que não devemos dar ao estudante um problema pronto para que resolva. Quando ele descobre por conta própria o problema, tem a possibilidade de movimentar o pensamento, buscando estabelecer conexões com outras instâncias e produzir novas situações problema.

Portanto, a atividade desta etapa consistiu numa investigação de campo, cujo objetivo era identificar como os professores de Educação Física, que atuam em diferentes contextos, entendem os conceitos de saúde e de promoção da saúde e se eles vêem possibilidades concretas de atuar como promotores de saúde em seus respectivos locais de trabalho. Para esta investigação a turma foi dividida em cinco grupos, cada um responsável por uma área de atuação da Educação Física: escolas, hospitais/postos de saúde, academias, projetos sociais, iniciação esportiva.

Foi elaborada uma entrevista semiestruturada para a coleta de dados, cujo objetivo era conhecer as ideias/ concepções de cada professor entrevistado acerca de saúde e promoção da saúde e verificar as possibilidades de promover a saúde no contexto em que o professor se inseria.

Num prazo determinado os grupos visitaram os locais escolhidos, entrevistaram os professores e, na medida do possível, observaram suas aulas, filmando ou fotografando quando foi permitido. Para socializar os dados encontrados, cada grupo sistematizou as respostas obtidas, elaborando uma apresentação de slides com tabelas, fotos, vídeos, etc., a ser exposta para o restante da turma.

Preparou-se um seminário, onde cada grupo apresentou a sua pesquisa, esclarecendo como se deu o processo de coleta de informações e explicando o relato de cada professor entrevistado, bem como as atividades observadas. As respostas dadas pelos professores foram confrontadas com os conceitos construídos pela turma a partir do estudo bibliográfico realizado no primeiro momento da disciplina.

Ao final das apresentações debateu-se acerca das situações apresentadas e realizou-se um diagnóstico dos problemas observados. Foi possível detectar falhas ou lacunas na formação do professor de Educação Física; atitudes equivocadas deste profissional no trato com a promoção da saúde; estrutura inadequada para o desenvolvimento de atividades voltadas à promoção da saúde, ideias e concepções 'cristalizadas' dos professores, diferenças nas ideias difundidas nos diferentes contextos visitados, etc.

A discussão das situações problema observadas foi uma atividade enriquecedora do ponto de vista da elucidação do contexto de atuação dos professores de Educação Física no que tange à promoção da saúde, pois apontou os limites e possibilidades deste campo de trabalho. Tal fato vai ao encontro das reflexões de Berbel (2011) quando afirma que aprender por meio da problematização e/ou da resolução de problemas de sua área, é 
uma das possibilidades de envolvimento ativo dos alunos em seu próprio processo de formação, preparando-se para o exercício profissional futuro.

\section{3 Terceiro momento}

A desconstrução de conceitos possibilitou uma ampliação de horizontes e (re) construção de novos conhecimentos, levando os alunos a pesquisar e refletir sobre as dificuldades em articular ou relacionar os conceitos de saúde e promoção da saúde com a prática do professor de Educação Física. De acordo com Silva (2011) a terceira e última etapa da problematização é de extrema importância. Nela os estudantes compartilham com o professor e a turma, as estratégias e soluções encontradas, discutem os resultados e sistematizam os conteúdos envolvidos. Esta etapa pode ser realizada por meio de uma apresentação oral onde os alunos expressam suas ideias, argumentam, questionam uns aos outros, desenvolvem o espírito crítico para análise e avaliação dos resultados, verificam as dificuldades nos processos e conceitos envolvidos e negociam significados. (SILVA, 2011, p. 27).

Neste sentido, a última etapa da disciplina se baseou nas discussões feitas durante todas as etapas anteriores, especialmente, nas reflexões sobre como promover a saúde através da Educação Física a fim de fazê-los pensar em novas proposições relacionadas com este tema específico: Como fazer 'promoção de saúde' nos diferentes contextos de atuação do professor de Educação Física? Para responder a esta pergunta, cada grupo (seguindo a divisão feita para a atividade anterior) elaborou algumas ações de promoção da saúde a serem aplicadas nos diferentes contextos de atuação do professor de Educação Física. A construção da atividade considerou a realidade observada durante a entrevista realizada na atividade anterior. Por exemplo: o grupo que entrevistou o professor de uma academia elaborou ações de promoção da saúde a serem desenvolvidas numa academia.

As apresentações foram teórico-práticas, além de explicar e discutir os princípios teóricos da ação e suas implicações para uma atuação comprometida com a promoção da saúde, o grupo aplicou a estratégia planejada ao restante da turma, que participou como se fossem alunos envolvidos naquela ação. O objetivo era formular hipóteses de solução para os problemas levantados na etapa anterior e testá-las a partir de uma simulação com a própria turma.

Como forma de avaliação, foi feita uma roda de conversa onde cada grupo apresentou as dificuldades encontradas na elaboração das ações para os diferentes contextos e o restante da turma, que havia participado como 'aluno', relatou suas impressões sobre o que vivenciou. O confronto entre o que o grupo planejou realizar como 'professor' e o que o restante da turma percebeu durante a vivência como 'alunos' gerou um debate intenso e possibilitou uma melhor compreensão dos limites e possibilidades da atuação do professor de Educação Física na área da Promoção da Saúde. O grupo pode perceber o quanto ainda é frágil e inacabada a proposta desta atuação, o que despertou uma curiosidade ainda maior na pesquisa e inserção na área.

\section{CONSIDERAÇÕES FINAIS}

O desenvolvimento da disciplina Atividade Física e Promoção da Saúde, descrito neste artigo, teve importância tanto para a formação dos alunos, futuros professores, como na formação da própria professora e principal autora deste manuscrito.

Na medida em que a disciplina foi se desenvolvendo através do estímulo à pesquisa, formulação de hipóteses e aplicação de propostas observou-se um maior interesse dos alunos por esta área de atuação. Foi interessante observar que a aplicação de metodologias ativas levou os discentes a refletirem sobre o seu processo de trabalho e a formulação de propostas de transformação desta realidade (Pedrosa et al., 2011). 
Os alunos demonstraram um importante aproveitamento das discussões realizadas durante a disciplina, a partir da atuação em situações reais, intervindo sobre a realidade, interagindo com diversos atores sociais, construindo coletivamente o conhecimento, valorizando os diferentes saberes e cenários de aprendizagem. Nos anos que se seguiram criaram um grupo de pesquisa para estudar questões que envolvem a Educação Física e a Saúde Coletiva; elaboraram artigos apresentados em diferentes eventos científicos que discutem o tema; desenvolveram um projeto de Promoção da Saúde para aulas de Educação Física escolar, etc. Além disso, vários alunos fizeram seus trabalhos de conclusão de curso (TCC) com temas relacionados à Promoção da Saúde na Educação Física, aproveitando as discussões e referências utilizadas na disciplina. Muitos prosseguiram com estudos na área da Promoção da Saúde, tentando os processos seletivos para a Residência Multiprofissional em Saúde ou para o Mestrado em linhas de pesquisa que discutem o assunto.

As atividades de pesquisa teórica e de campo e as discussões realizadas durante a disciplina tiveram importância fundamental na compreensão dos limites e possibilidades da atuação do professor de Educação Física na promoção da saúde, em seus diferentes contextos de atuação. Somente “mergulhando” no campo, através das pesquisas, entrevistas e observações, foi possível realizar as reflexões necessárias à construção de uma análise crítica da referida atuação.

\section{REFERÊNCIAS}

ABENEFS. Manifesto ABENEFS: Alinhando a formação inicial em Educação Física às necessidades do setor saúde. Associação Brasileira de Ensino da Educação Física para a Saúde (ABENEFS), 2016. Disponível em www.abenefs.com. Acesso em 31/01/2016.

BERBEL, Neusi A.N. A problematização e a aprendizagem baseada em problemas. Interface-Comum. Saúde Educ.; v.2, n.2, p.139-154,1998.

As metodologias ativas e a promoção da autonomia de estudantes. Semina: Ciências Sociais e Humanas, Londrina, v. 32, n. 1, p. 25-40, jan./jun. 2011.

BORGES, Marcos C. et al. Aprendizado baseado em problemas. Medicina, Ribeirão Preto, v.47, n.3, p. 301307, 2014. Disponível em http://revista.fmrp.usp.br/. Acesso em: 14 abr. 2016.

BORGES, Tiago S.; ALENCAR, Gidélia. Metodologias ativas na promoção da formação crítica do estudante: o uso das metodologias ativas como recurso didático na formação crítica do estudante do ensino superior. Cairu em Revista. Ano 03, nº 04, p. 119-143, 2014.

CECCIM, Ricardo B.; FEUERWERKER Laura C. M. Mudança na graduação das profissões de saúde sob o eixo da integralidade. Cad Saúde Pública; v.20, n.5, p.1400-1410, 2004.

CONTERNO, Solange F.R.; LOPES, Roseli E. Inovações do século passado: origens dos referenciais pedagógicos na formação profissional em saúde. Trab. Educ. Saúde, Rio de Janeiro, v. 11 n. 3, p. 503-523,set./dez. 2013.

CYRINO, Eliana G.; TORALLES-PEREIRA, Maria Lúcia. Trabalhando com estratégias de ensino-aprendizado por descoberta na área da saúde: a problematização e a aprendizagem baseada em problemas. Cad Saúde Pública; v.20, n.3, p.780-788, 2004.

DELLA BARBA, Patrícia C. S. et al. Formação inovadora em Terapia Ocupacional. Interface: Comunicação, Saúde, Educação, Botucatu, v. 16, n. 42, p. 829-842, 2012.

GARLET, Francieli R.; CARDONETTI, Vivien K.; OLIVEIRA, Marilda. A problematização como possibilidade avaliativa. Atos de Pesquisa em Educação, v. 9, n. 3, p. 662-680, 2014. 
KOMATSU, Ricardo S.; ZANOLLI, Maurício B.; LIMA, Valéria V. Aprendizagem baseada em problemas. MARCONDES, E.; GONÇALVES, E. (orgs). Educação médica. São Paulo: Sarvier, p. 223-37, 1998.

MARTINEZ, Cláudia M.S.; DELLA BARBA, Patrícia C.S. Motivação de alunos de graduação em Terapia Ocupacional no processo de aprender a aprender. In: Congresso Internacional PBL 2010 - aprendizagem baseada em problemas e metodologias ativas de aprendizagem, 2010, São Paulo. Anais. v. R0231, p.1-8. São Paulo, 2010.

MITRE, Sandra M. et al. Metodologias ativas de ensino-aprendizagem na formação profissional em saúde: debates atuais. Ciência \& Saúde Coletiva, Rio de Janeiro, v. 13, supl. 2, p. 2133-2144, 2008.

NETO, António J. Para uma didática das Ciências transdisciplinar: o contributo da Aprendizagem Baseada na Resolução de Problemas. Atas do Encontro sobre Educação em Ciências através da Aprendizagem Baseada na Resolução de Problemas. Braga, CIEd - UMinho, 2013.

PEDROSA, Ivanilda L. et al. Uso de metodologias ativas na formação técnica do agente comunitário de saúde. Trab. educ. saúde, Rio de Janeiro, v. 9, n. 2, p. 319-332, jul./out. 2011.

RIBEIRO, Iramara L.; JÚNIOR. Antônio M. Graduação em saúde, uma reflexão sobre ensino-aprendizado. Trab. educ. saúde. v.14 n.1, Rio de Janeiro, jan./mar. 2016.

SILVA, Luciana S. et al. Formação de profissionais críticos-reflexivos: o potencial das metodologias ativas de ensino aprendizagem e avaliação na aprendizagem significativa. Revista CIDUI. n.2, 2014. Disponível em www.cidui.org/revistacidui. Acesso em: 14 abr. 2016.

VASCONCELLOS, Maura. M. M.; BERBEL, Neusi. A. N.; OLIVEIRA, Cláudia. C. Formação de professores: o desafio de integrar estágio com ensino e pesquisa na graduação. Revista Brasileira de Estudos Pedagógicos, Brasília, v. 90, n. 226, p. 609-623, set./dez. 2009.

VIEIRA, Leila M. et al. Formação profissional e integração com a rede básica de saúde. Trab. educ. saúde. vol.14, $\mathrm{n}^{\circ}$ 1, Rio de Janeiro, jan./mar, 2016.

ZANOTTO, Maria A.; ROSE, Tânia. Problematizar a Própria Realidade: análise de uma experiência de formação contínua. Rev Educação e Pesquisa; v. 29, n.1, p. 45-54, 2003. 